\title{
Use of an inert marker (phenol red) to improve accuracy in gastric secretion studies
}

\author{
M. HOBSLEY 1 AND W. SILEN \\ From the Department of Surgery, University of California School of Medicine, and the Clinical Research \\ Center FR 83, San Francisco General Hospital, San Francisco, and the Department of Surgery, Harvard \\ Medical School, Beth Israel Hospital, Boston, USA
}

SUMMARY Gastric secretion from 24 subjects was collected by continuous nasogastric aspiration during the plateau of secretion evoked by intravenous histamine diphosphate, $0.01 \mathrm{mg} / \mathrm{kg} / \mathrm{hr}$. Simultaneously, phenol red was instilled at a constant rate into the proximal part of the stomach. Concentrations of phenol red in 15-minute aspirates were measured, and used to deduce pyloric losses and the reasons for random variation in the volumes aspirated.

The average coefficient of variation in the volume was $26 \%$, irrespective of the nature of the nasogastric tube. Correction by phenol red reduced this value to $21 \%$. The coefficient of variation of volume diminished as secretion rate increased. Pyloric losses amounted to $7 \mathrm{ml} / 15 \mathrm{~min}$, and were independent of the secretion rate. The quantitative effect of these errors upon the assessment of gastric secretion was minimal at high secretion rates but important at low rates.

Clinical studies designed to measure human gastric secretory activity rely upon the complete collection of the gastric secretion as an essential first step. The technique usually employed is continuous aspiration via a nasogastric tube, positioned so that its tip lies in the most dependent part of the stomach. Rovelstad (1963) showed that continuous aspiration, rather than intermittent, was essential to reduce the errors due to losses of gastric juice through the pylorus, but did not prove that this source of error was negligible if the aspiration was carried out continuously. Machine suction has been shown to be inferior to hand suction (Johnston and McCraw, 1958). Royle and Catchpole (1967) reported that considerable losses of gastric secretion did occur via the pylorus even during continuous aspiration; their measurements of these losses were indirect and inferential. The present article reports studies designed to measure pyloric losses under various conditions using a non-absorbable marker during a state of submaximal but constant secretory activity.

\section{PRINCIPLE OF THE MARKER TECHNIQUE}

A double-lumen tube is used: the main channel is used or aspiration, its tip lying in the most dependent part of the stomach, while the marker is instilled at a constant

${ }^{1}$ Please address requests for reprints to M. Hobsley, The Middlesex Hospital, London, England, W1. rate through the shorter channel to enter the stomach near the cardia. The marker mixes with the gastric secretion, which in the present studies has been maintained at constant rate, and when the mixture reaches the tip of the tube it is aspirated and collected. The amount of marker collected in one collection period is expressed as a fraction of the amount instilled during that period. This recovery fraction, $\mathbf{R}$, measures also the recovery fraction of the gastric juice secreted during the period, assuming that mixing is perfect.

Moreover, the concentration of the marker in the secretion lost via the pylorus is the same as the measured concentration, $\mathrm{C}$, of the marker in the aspirate; so the volume of the pyloric loss is calculable from the amount of marker lost, divided by the concentration, $\mathrm{C}$.

The extent to which this assumption of perfect mixing is justified depends upon what relationship is observed between the recovery fraction and the concentration of marker in gastric secretion collected during a run of several collection periods under steady-state conditions. Suppose first that mixing is perfect, but that the completeness of collection varies greatly between one period and the next: during the period of undercollection the recovery fraction, expressed as a percentage of the average recovery fraction for the whole run of samples, is low, while during the subsequent period of overcollection the recovery fraction is high; but in either event there is no reason why the concentration of the marker in the two samples should differ from the average. On the other hand, if mixing is not perfect, then a low recovery fraction in any one period may be due to an imperfect penetration of the marker to the collection zone 
and is then associated with a low concentration of marker in the aspirate. Subsequently, the excess marker left over from the first period may find its way into the next period's secretion, resulting in an increase both in the recovery fraction and in the concentration of marker above the average values. The test of perfect mixing, therefore, is that during constant secretory activity the concentration of the marker does not vary from one specimen to the next, even though the volumes of the specimens and consequently the recovery of the marker may vary widely.

The preceding remarks depend upon the basic assumption that the marker used is not destroyed or altered in any way in the stomach, and that it is not lost from the stomach by any route except via the pylorus, $i e$, that it is not absorbed through the stomach wall or adsorbed on to its surface.

\section{METHODS}

A steady submaximal state of gastric secretory activity was arrived at, using a continuous intravenous infusion of histamine diphosphate in a dosage of $0.01 \mathrm{mg} / \mathrm{kg}$ body weight $/ \mathrm{hr}$, delivered by a Harvard constantinfusion pump, ${ }^{1}$ into a slow drip infusion of $5 \%$ dextrose near the entry of the drip tubing into an arm vein. The subject fasted from midnight, swallowed the nasogastric tube, and then the infusion began at $8.00 \mathrm{am}$, with the subject semirecumbent at $45^{\circ}$, lying on his back. In the earlier studies the position of the tube was adjusted with the aid of fluoroscopy, but in the later studies reliance was placed on the recovery of at least $80 \%$ of $20 \mathrm{ml}$ water instilled into the emptied stomach. Gastric secretions were aspirated continuously by a Gumco suction pump, except that every five minutes 15 to $30 \mathrm{ml}$ of air was blown down the main lumen of the nasogastric tube from a bulb syringe arranged as a side arm to the suction line. The aspirate was divided into 15 -minute samples. A plateau of secretory activity, as judged by the volumes of 15minute samples, was reached after 30 to 60 minutes, and all results quoted in this paper are for plateau samples. Phenol red $0.15 \%$ solution, prepared as described by Hunt (1954), was instilled, using a similar constant-rate pump, at the rate of $0.05 \mathrm{ml} / \mathrm{min}$ into the upper part of the stomach. The phenol red channel was constructed from fine vinyl tubing, of internal diameter 0.020 in. and wall thickness 0.008 in., passed through a side hole down the main lumen of either a plastic, or plastic sump-type ${ }^{2}$ or rubber nasogastric tube, and brought to the exterior at a point 6 inches proximal to the most proximal aspirating hole in the main channel.

The volume of each 15-minute sample of gastric juice was measured, and the phenol red concentration estimated by simple spectrophotometric ${ }^{3}$ determination in alkaline solution at $550 \mathrm{~m} \mu$. For samples up to $70 \mathrm{ml}$ in volume, $1 \mathrm{ml}$ was alkalinized with $20 \% \mathrm{NaOH}$ and diluted to $25 \mathrm{ml}$. For larger samples, $2 \mathrm{ml}$ aliquots were treated similarly. At the end of the study when the

${ }^{1}$ Model 600/900

'Salem, Sheridan Corp, Argyle, N.Y.

${ }^{3}$ Bausch-Lomb. nasogastric tube had been removed from the subject a standard solution of phenol red was prepared: the amount of phenol red solution delivered by the Harvard pump through the extra lumen of the nasogastric tube in 15 minutes was collected in about $30 \mathrm{ml}$ water, alkalinized, diluted to $500 \mathrm{ml}$, and examined spectrophotometrically.

The fractional recovery, $\mathbf{R}$, of phenol red during each 15-minute period was calculated thus:

$$
\mathbf{R}=\frac{\mathbf{u} \times \mathbf{v}}{\mathrm{s} \times \mathbf{n}} \ldots \ldots \ldots \ldots \ldots \ldots
$$

where $\mathrm{u}=$ spectrophotometer reading of the sample

$\mathrm{v}=$ volume of sample $(\mathrm{ml})$

$\mathbf{s}=$ spectrophotometer reading of the standard, adjusted as described below

$\mathrm{n}=$ ratio of dilutions of whole standard and $1 \mathrm{ml}$ of the gastric sample, ie, $500 / 25=20$ for samples up to $50 \mathrm{ml}$ in volume, $500 / 12 \cdot 5=$ 40 for larger samples. The derivation of this formula is given in the Appendix.

For each sample of a run of samples obtained during the plateau of secretory activity in each study, the following indices were calculated:

$$
\begin{aligned}
\text { Recovery index } & =\log \left(\frac{R \text { sample }}{R \text { average }} \times 100\right) \ldots \\
\text { Concentration index } & =\log \left(\frac{\mathrm{u} \text { sample }}{\text { u average }}=100\right) \ldots
\end{aligned}
$$

The reasons for expressing these indices logarithmically are that ratios are not distributed normally and are subject to disproportionate variations at the extremes of their ranges; the logarithmic transformation of variables exhibiting these tendencies is standard statistical practice.

For each run the average 15-minute loss of gastric juice through the pylorus was calculated as:

$$
\text { Loss }=\frac{1-\mathbf{R}}{\mathbf{R}} \times \mathrm{V} \text { average }
$$

The measurement of $s$, the spectrophotometric reading of the standard, requires special consideration. Measured as described, the value obtained represents a single observation and is therefore particularly susceptible to observational error. One way of improving accuracy would be to make several standards with several consecutive 15-minute deliveries of phenol red at the end of each study. This would be time-consuming. The alternative approach has therefore been adopted of correcting the reading of $s$ obtained on any one day by the regression against time of the values of $s$ obtained on all the other days during the course of this investigation.

\section{CLINICAL MATERIAL}

Studies were done upon 24 volunteers who were patients in surgical wards. Two (nos. 23 and 24) were women, aged 41 and 47 years. Both had recently had acute cholecystitis which had settled completely by the time they were studied; subsequently at laparotomy no abnormality of the stomach or duodenum was found. The remaining 22 subjects were men, aged 21 to 57 years, 
average 43.4 years. Twelve men had been admitted to hospital for reasons unconnected with the gastrointestinal tract: they denied having significant digestive symptoms. Six had digestive disorders, but previous or subsequent laparotomy yielded no evidence of peptic ulceration. The diagnosis in three of these patients (nos. 1, 4, and 18) was gallstones, in two (nos. 17 and 22) it was pancreatitis, while in the sixth (no. 10), a Chinaman, the cause of his recent melaena was not discovered. Barium meal examination in these last three patients revealed no peptic ulceration. Of the remaining four subjects, two had duodenal ulcers and two gastric ulcers.

\section{STUDIES IN VITRO}

The identical stock solution of phenol red was used throughout the nine months of the present study. The spectrophotometric density of the standard solution prepared from this stock standard on any particular day was considered in relation to the age of the stock standard.

The clinical studies involved not only delivery of the phenol red, but its subsequent collection by aspiration from a reservoir (the stomach). The probable accuracy of such collections was tested by an in-vitro model in which a double-lumen nasogastric tube was inserted into a $250 \mathrm{ml}$ conical flask. Phenol red was instilled from the pump as usual down the shorter tube, gastric secretion was simulated by a stream of water conducted at about $2 \mathrm{ml} / \mathrm{min}$ from a reservoir to the flask by intravenous infusion tubing, and 15-minute collections of the resultant mixture were aspirated via the longer tube.

\section{RESULTS}

REPRODUCIBILITY OF VOLUMES COLLECTED Table I gives the data on the reproducibility of the volumes of repeated 15-minute samples during runs of collection at constant gastric secretory rate. For each run of samples, the following statistical indices are given: arithmetic mean, standard deviation, and coefficient of variation

$$
\left(=\frac{\mathrm{SD}}{\text { average }} \times 100\right)
$$

Table I has been constructed to give the data separately for plastic sump, plastic non-sump, and rubber non-sump nasogastric tubes. In Table II, both types of non-sump tube together are compared with the sump type. Table II shows that the average standard deviation of the volumes of repeated samples was rather higher $(12.82 \mathrm{ml} / 15 \mathrm{~min})$ with non-sump than with sump tubes $(9.59 \mathrm{ml} / 15 \mathrm{~min})$. However, the difference of $3.23 \mathrm{ml} / 15 \mathrm{~min}$ was not statistically significant by the $t$ test. Moreover, plots of the results (Figs. 1 and 2) indicate that the standard deviation of repeated samples tends to increase with the average size of the sample $(\mathrm{SD}=$
TABLE I

INFLUENCES OF TYPES OF NASOGASTRIC TUBE UPON VARIATIONS IN VOLUME OF REPEATED SAMPLES DURING RUNS AT CONSTANT SECRETION RATE

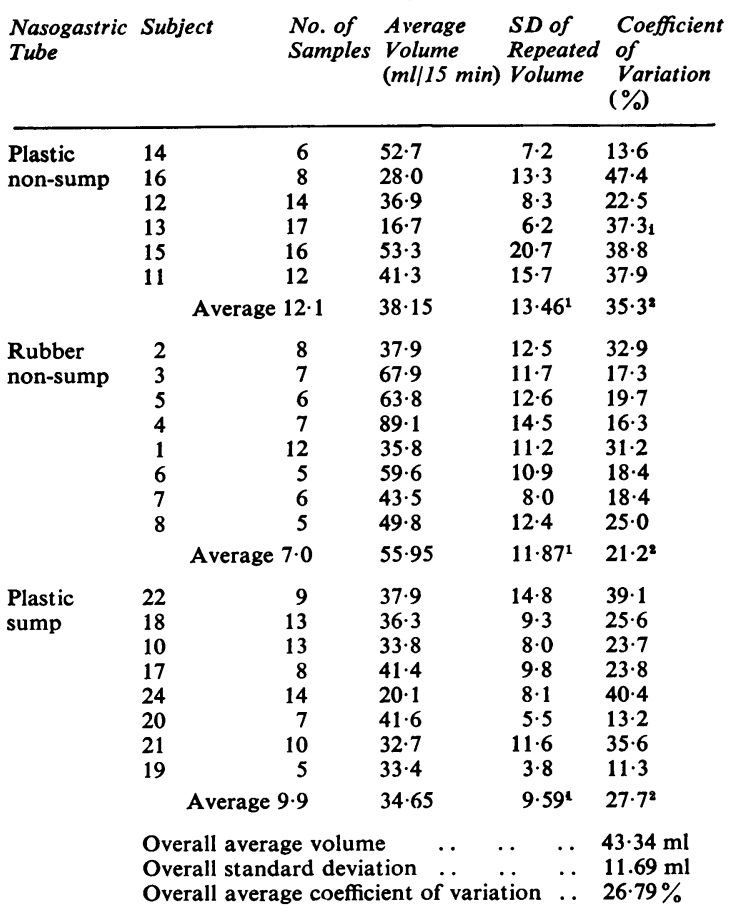

${ }^{1}$ These values are not simple arithmetical means of the SDs of the results in each individual subject of the group. They were calculated as follows:

When $x_{i j}$ is the volume of the $i^{\text {th }} 15$-minute sample in subject $j$, $\bar{x}_{1}$ is the mean for the subject $j$,

$\mathrm{n}$ is the total number of 15 -minute samples in all the subjects

$\mathrm{n}^{\prime}$ is the number of subjects,

then average standard deviation $=\sqrt{\frac{\left(x_{1 j}-\bar{x}_{j}\right)^{2}}{n-n^{\prime}}}$

${ }^{2}$ Average coefficient of variation $=$

average SD as obtained above $\times 100$

average vol/15 min

$6.62+0.095 \mathrm{~V} ; \mathrm{r}=0.40 ; \mathrm{P}<0.05)$ and the difference between the average standard deviations of the non-sump and sump tubes was probably due to the fortuitous occurrence of a higher average secretion rate in the studies with non-sump than in the studies with sump tubes. This interpretation is supported by the finding (Table II) that the average coefficients of variation of repeated samples with the two types of tube are practically identical ( 27.68 for sump tubes, 26.53 for non-sump tubes).

An important deduction from Fig. 3 is that the coefficient of variation decreases as the average volume increases (coefficient of variation $=41.66-$ $0.34 \mathrm{~V} ; \mathrm{r}=0.54 ; \mathrm{P}<0.05)$, so that the greater the 


\section{TABLE II}

COMPARISON OF VARLATIONS IN VOLUME OF REPEATED SAMPLES DURING RUNS AT CONSTANT SECRETION RATE IN SUMP AND NON-SUMP TUBES

\begin{tabular}{|c|c|c|c|c|c|}
\hline Type of Tube & No. of Studies & $\begin{array}{l}\text { Average No. } \\
\text { of Samples/Run }\end{array}$ & $\begin{array}{l}\text { Average Volume } \\
(\mathrm{ml} / 15 \mathrm{~min})\end{array}$ & $\begin{array}{l}\text { Average } S D \text { of } \\
\text { Repeated Volumes }\end{array}$ & $\begin{array}{l}\text { Average Coefficient of } \\
\text { Variation of Repeated } \\
\text { Volumes }\end{array}$ \\
\hline $\begin{array}{l}\text { Sump tubes } \\
\text { Non-sump tubes }\end{array}$ & $\begin{array}{c}8 \\
14\end{array}$ & $\begin{array}{l}9 \cdot 9 \\
9 \cdot 3\end{array}$ & $\begin{array}{l}34 \cdot 65 \\
48 \cdot 32\end{array}$ & $\begin{array}{c}9 \cdot 59^{1} \\
12 \cdot 82^{1}\end{array}$ & $\begin{array}{l}27 \cdot 68^{1} \\
26 \cdot 53^{1}\end{array}$ \\
\hline Difference in SDs & $\begin{array}{l}=3.23 \\
=1.94 \\
=20 \\
10>P>0.05\end{array}$ & & & & \\
\hline
\end{tabular}

These values were calculated as described in the footnote to Table I.

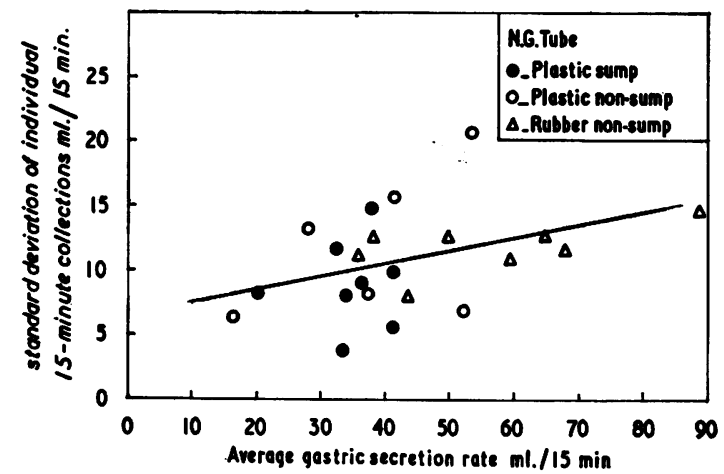

FIG. 1.

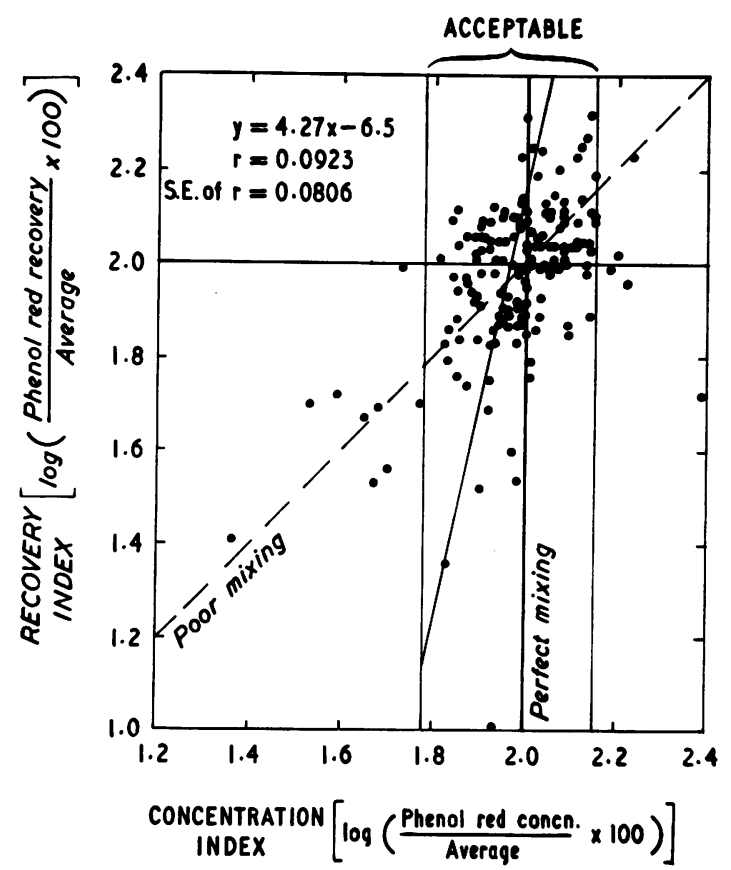

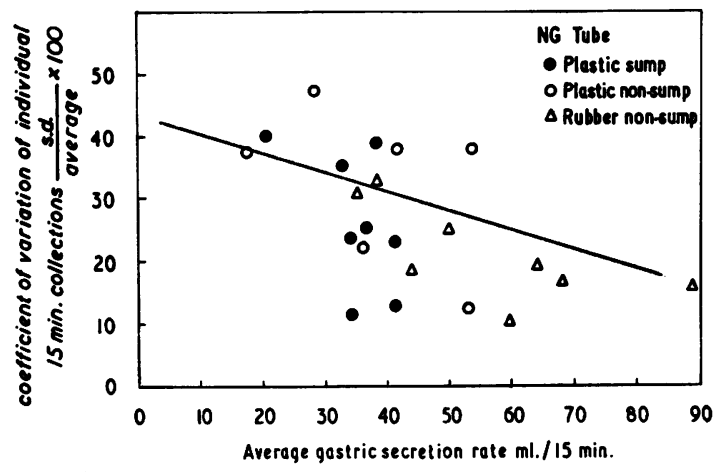

FIG. 2.

FIG. 1. Relation between average secretion rate and standard deviation of volumes of individual 15-minute samples.

FIG. 2. Relation between average secretion rate and coefficient of variation of volumes of individual 15-minute samples.

FIG. 3. Relation between concentration and recovery rate of phenol red. The line marked 'perfect mixing' represents all samples in a run whose phenol red concentration is identical with (ie, $100 \%$ of) the average value, and therefore has a concentration index of $2 \cdot 0$ $(\log 100=2)$. Similarly, the unlabelled horizontal line representing a recovery index of 2.0 describes all samples for which recovery does not vary from the average recovery for the run, ie, mixing is perfect, no sequestration occurs, pyloric losses are constant, and only the secretion rate varies.

FIG. 3. 
rate of secretion the less likely are true changes in secretion rate to be masked by errors of collection.

The conclusions drawn from these data on reproducibility are that (1) the nature of the nasogastric tube, whether of the sump pattern or not, and whether made of rubber or plastic, has no influence on the reproducibility of the collections of 15minute samples during constant secretory activity; (2) reproducibility is easier to achieve at higher secretion rates; and (3) reproducibility is probably better assessed by the coefficient of variation than by the straightforward standard deviation.

PHENOL RED STUDIES First, the spectrophotometric absorption of standard solutions prepared at intervals during nine months gradually diminished. The spectrophotometer reading $(y)$ was dependent on the age in days of the stock standard solution $(x)$ according to the equation

$y=-0.00021 x+0.3876(\mathrm{r}=-0.524 ; \mathrm{P}<0.05)(5)$

The calculated regression line of these data was finally used in retrospect, rather than the value actually obtained on the day of each study, to obtain the greatest possible accuracy in the calculation of recovery, and hence of the volumes of pyloric losses, by equation 4 .

Secondly, the variability of collection of the instilled phenol red by continuous aspiration in the model was assessed by expressing the spectrophotometric density of each 15-minute collection as a percentage, and as the logarithm of the percentage of the mean value for the run of collections. In 36 such collections the percentage varied between 57 and $120 \%$, and the standard deviation of the difference from 100 was $15 \%$. Expressed in terms of the logarithm of the percentage, the variation was 1.73 to 2.08 , and the SD of the difference from 2.00 was 0.0625 . These figures, then, represent the quantitative error in the model inherent in the difficulties of ensuring immediate and complete aspiration from a chamber of all the phenol red instilled into the chamber. These errors are presumably at least as great when the human subject is substituted for the model.

The phenol red data in the clinical studies may now be presented against this background. The arguments presented in the introduction show that, provided the phenol red mixes well with the stomach contents before aspiration, there is a complete dissociation between recovery of phenol red and its concentration in the aspirate, ie, even when the recovery is variable the concentration should not alter. The data are therefore presented in Fig. 3 on a diagram where the horizontal axis represents the concentration index (as defined by equation 3), and the vertical axis represents the recovery index (as defined by equation 2). Each 15-minute sample obtained throughout the present study represents a single point on this plot.

If mixing is perfect and secretion rate is constant, then the concentration index cannot vary. Recovery, however, may vary from one sample to the next because of intermittent sequestration of the phenol red/gastric juice mixture between gastric rugae. Samples exhibiting true mixing should therefore lie grouped vertically along the line representing the average phenol red concentration: this line is marked 'perfect mixing' in Figure 3. The reality of intermittent sequestration is thus attested to by the vertical distribution of points in Figure 3. On the other hand, when mixing is poor a low recovery index is associated with a low concentration index, a high recovery index with a high concentration index, and such points are necessarily grouped along the $45^{\circ}$ diagonal marked 'poor mixing'. It will be seen that a few samples fall clearly into this category. Finally, if secretion rate alone varies, samples will be along the horizontal line representing constant recovery with varying concentration.

The question arises, How may one distinguish between samples in which mixing is, or is not, adequate? An answer is provided by the studies in vitro: the inevitable errors in collecting the instilled phenol red by aspiration had a standard deviation of $15 \%$, and the phenol red concentration of consecutive samples may be expected to vary by this amount from the average for the run, without the necessity to postulate either any alteration in secretion rate or any failure of mixing. For studies in vivo we have thought it wise to assume that the inevitable errors might be larger, and have arbitrarily chosen a standard deviation of $20 \%$. Any particular sample may be expected to deviate by \pm 2 SD from the average, so that the concentration fraction may be 60 to $140 \%$, and the concentration index 1.78 to 2.15. In the figure (Fig. 3) the band representing this variation is marked 'acceptable', and all 154 samples lying within this band demonstrate that the phenol red has mixed well with the gastric juice. Most of the 17 samples outside this band lie near the line of poor mixing, although four lie near the horizontal representing average recovery and suggest that the secretion rate was changing. The data of Fig. 3 are the justification for using phenol red in the manner of the present studies, since they show that mixing is adequate in $90 \%$ of samples.

The regression line calculated for all acceptable samples is also shown in the diagram. The correlation coefficient of this line is very small 
( $r=0.0923$ ), thereby confirming that there is very little association between recovery index and concentration index, and there is therefore no statistical significance in the slight deviation of the regression line from the vertical.

VOLUME CORRECTION BY PHENOL RED For samples with phenol red concentrations within $40 \%$ of the average value, variations in the recovery rate can be ascribed to sequestration errors: a low recovery in one period, due to the trapping of a portion of the gastric secretion within a temporary loculus, may be succeeded in the next sample by an exaggerated recovery due to the freeing of the contents of the loculus. Over the whole run of collections, these variations in recovery rate cancel each other out, and it can be assumed that the average recovery rate for the whole run would have applied to each individual sample had sequestration not occurred. It follows that a correction for sequestration can be made by the formula:

$\begin{gathered}\text { Corrected } \\ \text { volume }\end{gathered}=\begin{gathered}\text { observed } \\ \text { volume }\end{gathered} \times \frac{\text { average recovery rate }}{\text { sample recovery rate }}$

It must be emphasized that there is no justification for using this formula with samples of phenol red differing from the mean by more than $40 \%$.

The correction by this method was applied to the data of Table I, as follows: in each run, any sample with a concentration index less than 1.78 or greater than 2.15 was rejected. The average recovery rate of the remaining acceptable samples was then calculated. The volumes of the acceptable samples were then corrected by equation 6 . Using the corrected volumes of acceptable samples, and the measured volumes of any unacceptable samples, the standard deviation and coefficient of variation for each run was recalculated. These statistical indices for both the uncorrected and the phenol red corrected values are given in Table III. The overall average coefficient of variation for the corrected volume was $20.87 \%$, while the corresponding figure for the uncorrected volume was $26 \cdot 23 \%$. Using the $t$ test for paired comparisons, the mean difference between each pair was $6 \cdot 23$, the standard error of the differences was $1.79(\mathrm{t}=3.48, \mathrm{n}=16, \mathrm{P}<0.01)$. That is, the phenol red corrections applied as described above produce a small $(23 \%)$ but definite correction of the errors of collection. This is the extent of the advantage to be gained when one 15-minute collection is assessed against the average for a run; another, and more powerful method of using the phenol red technique is available when the average for one run is compared with the average for another run, and will be described in a subsequent paper.
TABLE III

VARIATIONS IN VOLUMES OF REPEATED SAMPLES DURING RUNS AT CONSTANT SECRETION RATE CORRECTED BY PHENOL RED DATA ${ }^{1}$

\begin{tabular}{|c|c|c|c|}
\hline Subject & $\begin{array}{l}\text { SD of Repeated } \\
\text { Volumes }\end{array}$ & $\begin{array}{l}\text { Coefficient of } \\
\text { Variation }\end{array}$ & $\begin{array}{l}\text { Coefficient of } \\
\text { Variation } \\
\text { Uncorrected-Corrected }\end{array}$ \\
\hline 14 & $\begin{array}{l}7 \cdot 2 \\
8 \cdot 6\end{array}$ & $\begin{array}{l}14.9 \\
26.6\end{array}$ & $\begin{array}{r}-1.3 \\
8.4\end{array}$ \\
\hline 12 & - & - & - \\
\hline 13 & $4 \cdot 5$ & 25.8 & $11 \cdot 5$ \\
\hline 15 & $7 \cdot 8$ & 14.0 & $12 \cdot 8$ \\
\hline 11 & 10.9 & $26 \cdot 0$ & 11.9 \\
\hline 2 & $5 \cdot 5$ & $14 \cdot 1$ & 18.8 \\
\hline 3 & $6 \cdot 1$ & $9 \cdot 0$ & $8 \cdot 3$ \\
\hline 5 & $8 \cdot 6$ & $13 \cdot 5$ & $6 \cdot 2$ \\
\hline 4 & $13 \cdot 3$ & 14.7 & $1 \cdot 6$ \\
\hline 1 & $8 \cdot 2$ & $23 \cdot 5$ & $7 \cdot 7$ \\
\hline 6 & - & - & - \\
\hline 7 & $6 \cdot 4$ & 15.9 & $2 \cdot 5$ \\
\hline 8 & - & - & - \\
\hline 22 & $12 \cdot 3$ & $32 \cdot 5$ & $6 \cdot 6$ \\
\hline 18 & 8.0 & $21 \cdot 6$ & $4 \cdot 0$ \\
\hline 10 & $12 \cdot 2$ & $35 \cdot 0$ & $-11 \cdot 3$ \\
\hline 17 & 10.8 & $24 \cdot 5$ & -0.7 \\
\hline 24 & $4 \cdot 3$ & $21 \cdot 2$ & $19 \cdot 2$ \\
\hline 20 & $7 \cdot 0$ & 16.5 & $-3 \cdot 3$ \\
\hline 21 & $8 \cdot 6$ & $26 \cdot 3$ & $9 \cdot 3$ \\
\hline 19 & - & - & - \\
\hline Average & & $20 \cdot 87$ & $6 \cdot 23$ \\
\hline
\end{tabular}

SE of difference between coefficients of variation $=1.79$

$$
\begin{array}{ll}
\mathbf{t} & =3.48 \\
\mathbf{n} & =16 \\
\mathbf{P} & <0.01
\end{array}
$$

${ }^{1}$ The values are to be compared with the last two columns Table I.

PYLORIC LOSSES The volume of gastric contents lost via the pylorus during 15 minutes of each run was calculated from the volume aspirated and the fraction of phenol red lost as described earlier. The results are shown in Table IV and Figure 4. Figure 4 shows the fractional loss of phenol red in relation to the 15-minute volume of aspirate: it is clear that the fraction of phenol red lost decreases as the rate of gastric secretion increases. At very low rates of aspiration, approaching $10 \mathrm{ml} / 15 \mathrm{~min}$, the loss may amount to nearly half the instilled dose, but when the

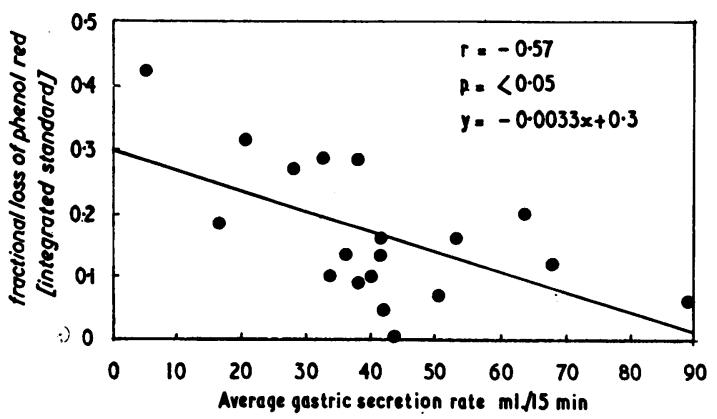

FIG. 4. Relation between average secretion rate and fractional loss of phenol red. 
TABLE IV

RATE OF GASTRIC SECRETION (ASPIRATED), FRACTIONAL LOSS OF PHENOL RED, AND CALCULATED PYLORIC LOSS EACH 15 MINUTES

\begin{tabular}{|c|c|c|c|}
\hline Subject & $\begin{array}{l}\text { Volume of Aspirate } \\
(\mathrm{ml} / 15 \mathrm{~min})\end{array}$ & $\begin{array}{l}\text { Fractional Loss of } \\
\text { Phenol Red (Adjusted } \\
\text { for Fading of Standard) }\end{array}$ & $\begin{array}{l}\text { Volume of } \\
\text { Pyloric Loss } \\
\text { (ml/15 min) }\end{array}$ \\
\hline $14^{2}$ & $50 \cdot 3$ & 0.069 & 3.7 \\
\hline 16 & $28 \cdot 0$ & 0.271 & 10.4 \\
\hline $12^{2}$ & - & - & - \\
\hline 13 & 16.7 & 0.119 & 3.8 \\
\hline 15 & $53 \cdot 3$ & $0 \cdot 160$ & $10 \cdot 2$ \\
\hline 11 & $41 \cdot 3$ & $0 \cdot 160$ & 7.9 \\
\hline 2 & 37.9 & 0.285 & 17.9 \\
\hline 3 & 67.9 & $0 \cdot 121$ & $9 \cdot 3$ \\
\hline 5 & $63 \cdot 8$ & 0.206 & $16 \cdot 6$ \\
\hline 4 & $89 \cdot 1$ & 0.061 & 5.9 \\
\hline 1 & $35 \cdot 8$ & 0.132 & 5.9 \\
\hline $6^{2}$ & - & - & - \\
\hline 7 & $43 \cdot 5$ & 0 & 0 \\
\hline $8^{2}$ & - & - & - \\
\hline 22 & 37.9 & 0.090 & $3 \cdot 8$ \\
\hline $18^{1}$ & $40 \cdot 1$ & 0.097 & $4 \cdot 3$ \\
\hline 10 & 33.8 & 0.098 & $3 \cdot 7$ \\
\hline 17 & $41 \cdot 4$ & $0 \cdot 135$ & 6.4 \\
\hline 24 & $20 \cdot 1$ & 0.314 & $9 \cdot 2$ \\
\hline 20 & $41 \cdot 6$ & 0.043 & $1 . \overline{8}$ \\
\hline 21 & $32 \cdot 7$ & 0.288 & $13 \cdot 2$ \\
\hline $19^{2}$ & - & - & - \\
\hline $23^{3}$ & $\begin{array}{l}5 \cdot 1 \\
\text { (Average } 41 \cdot 1 \text { ) }\end{array}$ & $\begin{array}{l}0.424 \\
\text { (Average 0.162) }\end{array}$ & 3.7 \\
\hline
\end{tabular}

Average pyloric loss $=7.1 \mathrm{ml} / 15 \mathrm{~min}$

$$
\mathrm{SD}=4.52 \mathrm{ml} / 15 \mathrm{~min}
$$

${ }^{1}$ In studies 14 and 18 the figures for secretion rate differ from the corresponding figures in Table $I$, because not all the samples whose SD was assessed in Table I contained phenol red, $i e$, the instillation of phenol red was started after the plateau had been reached.

${ }^{2}$ Studies $6,8,12$, and 19 were technically unsatisfactory with regard to phenol red, because of errors made in handling the preparation of the standards or of the diluted samples of gastric juice.

'Study 23 is not reported in Table I because there were not sufficient samples for assessiny standard deviation, etc.

aspiration rate exceeds $50 \mathrm{ml} / 15 \mathrm{~min}$, the fraction lost is less than a fifth. On the other hand, the actual volume lost per 15 minutes bears no clear relationship to the rate of aspiration: in fact, the rate of pyloric loss seems to be roughly constant, with an average value of $7.1 \mathrm{ml} / 15 \mathrm{~min}$ and a standard deviation of 4.52 , and it is independent of the rate of secretion.

\section{DISCUSSION}

The investigation described in this paper has analysed the errors incurred when gastric secretion is studied by continuous aspiration and has attempted to quantify these errors. The exact technical procedure used differed from that usually recommended and accepted by workers in this field in three respects: the use of machine rather than hand suction, the position of the subject, and the positioning of the tube. Machine suction has been shown to be inferior to hand suction (Johnston and McCraw, 1958) because of a tendency for the nasogastric tube to become blocked intermittently. Our pro- cedure for clearing the tube every five minutes by air insufflation was designed to circumvent this difficulty and appeared to work well. The position of the subject and the positioning of the tube will be discussed later: for the moment, the results obtained will be considered simply in relation to the exact technique used in this study.

Some of our results depend upon the use of phenol red as a marker, while others do not: the groups of findings will be discussed separately.

CONClusions NOT INVOLVING PHENOL ReD During apparently steady-state conditions, aspiration yielded variable results from one 15 -minute period to the next. At the rather low rates of secretion encountered with submaximal stimulation the coefficient of variation was $27 \%$. Gastric secretion tests as commonly performed assess secretion rates in terms of four samples taken during one hour, so the standard error of the resultant average $(27 / \sqrt{4})$ is $13 \frac{1}{2} \%$. This means that the secretory rates of two subjects do not certainly differ unless the difference between the averages is about $38 \%$. Since we are testing here the hypothesis that there is no difference between the two average volumes, the $t$ test may be applied to the percentage standard deviations just as well as to the standard deviations themselves. So the standard error of the difference between the means is

$$
\sqrt{\frac{\left(\mathrm{SD}_{1}\right)^{2}}{\mathrm{n}_{1}}+\frac{\left(\mathrm{SD}_{2}\right)^{2}}{\mathrm{n}_{2}}} \%=19 \cdot 1 \%
$$

and the difference between the means must exceed a value at least twice this amount in order to achieve significance at the $95 \%$ level. In absolute terms, if one patient secretes $50 \mathrm{ml} / 15 \mathrm{~min}$, another may secrete as little as $31 \mathrm{ml}$ or as much as $69 \mathrm{ml} / 15 \mathrm{~min}$ and the difference may still only have been due to experimental error. If the test is carried out with a single subcutaneous injection of secretagogue, so that a further factor of changing rates of secretion during the hour is introduced, the discriminatory power of the test is likely to be even further reduced.

The assessment of factors affecting reproducibility is modified by the observation that standard deviations of the 15-minute collections were proportional to the average volume. The possible factors affecting accuracy are, therefore, better studied in relation to the coefficient of variation rather than in relation to standard deviation.

Table I shows clearly that the non-sump tubes tested were no less efficient than the sump tubes. At first glance, rubber non-sump tubes appeared to perform better than the plastic non-sump tubes but the overall regression between coefficient of variation and volume must be taken into account (coefficient 
of variation $=41.66-0.34 \mathrm{~V}$ ). The fortuitously small average volume of $38.15 \mathrm{ml} / 15$ minutes in the plastic non-sump series would be expected, on the basis of this equation, to have a coefficient of variation of $28.7 \%$ compared with the observed $35.3 \%$. The difference is not significant. The larger average volume of $55.95 \mathrm{ml} / 15 \mathrm{~min}$ would be expected to have a coefficient of variation of $22 \%$ which is almost identical with the observed value. So it is unlikely that the rubber tubes really performed better than the plastic.

CONCLUSIONS INVOLVING PHENOL RED Interpretation of these studies depends upon whether phenol red is a true marker. However, there were two groups of observations involving different sets of assumptions. For the first group it was unnecessary to assume a $100 \%$ recovery provided that the actual recovery was consistent. In the second group an assumption of $100 \%$ recovery was made.

Consistent recovery Provided recovery was consistent, important deductions could be made from the relative constancy of phenol red concentration in repeated samples even though the recovered volume and therefore the recovery fraction altered. Constant concentration implied that the instilled phenol red was diluted by a constant volume of gastric juice and, therefore, that secretion rate was constant and mixing adequate. The only alternative possibility that alterations in secretion rate were masked by simultaneous alterations in mixing seems most unlikely. Alterations in recovery rate at constant phenol red concentration can only be explained by sequestration or by alterations in the rate of pyloric loss, but the average pyloric loss was very much smaller than the fluctuations observed. The data (particularly Fig. 3) show that secretion rate was reasonably constant (SD $\pm 20 \%$ in $97 \%$ samples) and that mixing was adequate in $89 \%$.

In 17 samples phenol red concentration altered. In the four samples where recovery did not change, the cause of the discrepancy was presumably a change in secretion rate; in the other 13, low recoveries were associated with low concentration and vice versa, and poor mixing is the likely explanation. Samples suspected of poor mixing or changing secretion rate could be detected by plotting their phenol red concentration and recovery parameters in Figure 3.

The correction of observed volumes by phenol red data reduced the overall coefficient of variation of repeated volumes to $20.8 \%$. Calculations similar to those above show that the standard error of the mean, calculated from an hour's output of gastric juice, was thereby improved from $13 \frac{1}{2}$ to $10 \%$. This is a small but useful improvement.
Complete recovery This condition has been assumed in calculating the pyloric loss by the formula:

Pyloric loss $(\mathrm{ml} / 15 \mathrm{~min})=$ collected vol $(\mathrm{ml} / 15 \mathrm{~min})$

$$
\begin{aligned}
\times\left(\frac{1-\mathbf{R}}{\mathrm{R}}\right) \\
\text { where } \mathbf{R}=\frac{\text { recovered phenol red }}{\text { instilled phenol red }} .
\end{aligned}
$$

If there is a systematic loss of phenol red by some route other than through the pylorus, so that the expected recovery of phenol red in the absence of any pyloric loss is, say, $\mathrm{n} \times$ (instilled phenol red), then the correct value for $\mathrm{R}$ to be used in the above equation is

$$
\mathbf{R}=\frac{\text { recovered phenol red }}{\mathrm{n} \times \text { (instilled phenol red })},
$$

Bloom, Jacobson, and Grossman (1967) have provided evidence that in Heidenhain pouches of dogs driven to secrete by histamine the recovery of phenol red is at least $95 \%$. The only data available from the human subject are those of Penner, Hollander, and Saltzman (1938) who claimed $100 \%$ recovery from the stomach when emptying was inhibited by instilling fat into the duodenum. Even if this early evidence is rejected (and the fact that recovery was $100 \%$ in one of our patients (Table IV) supports their finding), and the lower limit of Bloom's results, $95 \%$, is accepted, our estimate that loss via the pylorus averages $7 \cdot 1 \mathrm{ml} / 15 \mathrm{~min}$ is only $2.6 \mathrm{ml}$ too high. There would seem to be little doubt that there is an appreciable pyloric loss during continuous gastric aspiration.

Since the rate of pyloric loss appears to be independent of secretion rate, the effect of such a loss is proportionately much less at high than at low rates of secretion. Like the reduced coefficient of variation at high rates of secretion, the fixed rate of pyloric loss implies that the errors of tests of gastric function are likely to be least when the rate of gastric secretion is maximal.

One further aspect of this study requires comment. Our procedure for performing gastric aspiration differed in two respects from what is usually recommended. Firstly, radiological screening was not used to ensure that the tip of the tube was lying in an optimal position within the stomach. Our experience in this regard agrees with that of Lawrie, Smith, and Forrest (1964), namely, that screening is unnecessary for continuous infusion studies. Secondly, the subjects lay semirecumbent on their backs rather than on the left side. The original reason for choosing this position was that the studies recorded here were part of a larger investigation for which 
the position on the left side would have been unsatisfactory. A formal investigation, both of the effect of posture and also of the effect of radiological positioning of the tube upon the recovery of gastric juice, is now under way. We accept that the sources of error in the technique we have used might have been smaller if the postioning of the tube and of the subject had been conventional.

The advantages of the phenol red technique are that it demonstrates errors of collection and simultaneously allows their correction. Such errors of collection are liable to occur with any technique, but if a method of correction is incorporated in the test procedure it is no longer necessary to employ every expedient which might possibly improve recovery. There are obvious advantages in avoiding the need for radiological screening, and in allowing the subject to be comfortable rather than confining him to a single posture for several hours.

This investigation was supported by US Public Health grant AO-5616.

One of us (M.H.) was Comyns Berkeley Fellow of Gonville and Caius College, Cambridge, England, and The Middlesex Hospital Medical School, London, England, 1965-66, and Howard C. Naffziger surgical research fellow of the University of Calıfornia School of Medicine, San Francisco, 1966. The technical assistance of Miss Ivy Fey is gratefully acknowledged.

\section{REFERENCES}

Bloom, D. S., Jacobson, E. D., and Grossman, M. I. (1967). Validation of dilution indicators in the stomach. Gastroenterology, 52, 205-210.

Hunt, J. N. (1954). The inhibitory action of sucrose on gastric digestive activity in patients with peptic ulcer. Guy's Hosp. Rep., 103, 161-173.

Johnston, D. H., and McCraw, B. H. (1958). Gastric analysis: evaluation of collection techniques. Gastroenterology, 35, 512-516.

Lawrie, J. H., Smith, G. M. R., and Forrest, A. P. M. (1964). The histamine-infusion test. Lancet, 2, 270-273.
Penner, A., Hollander, F., and Saltzman, M. (1938). The gastric absorption of phenol red in humans. Amer. J. dig. Dis., 5, 657-661.

Rovelstad, R. A. (1963). Gastric analysis. Gastroenterology, 45, 90-107.

Royle, J. P., and Catchpole, B. N. (1967). Critical evaluation of the assessment of maximal gastric secretion stimulated by histamine. Brit. J. Surg., 54, 56-63.

\section{Appendix}

The formula for calculating the fractional recovery of phenol red (equation 1) was derived as follows:

Let the amount of phenol red delivered each 15 minutes be $P$

Let the recovery fraction be $R$

Then the amount of phenol red recovered is $\mathbf{R} \times \mathbf{P}$

Concentration of phenol red in standard $=$

$P$ (because the amount of phenol red de$\overline{500}$ livered by the pump is diluted to $500 \mathrm{ml}$ )

Concentration of phenol red in aspirated juice $=$

$$
\frac{\mathbf{R} \times \mathbf{P}}{\mathbf{V}}(\mathbf{V}=\text { volume of sample in } \mathrm{ml})
$$

So the concentration of phenol red in gastric juice diluted $1 / 25=$

$$
\frac{\mathrm{R} \times \mathrm{P}}{\mathrm{V} \times 25}(\text { if } \mathrm{V}<70 \mathrm{ml})
$$

$\therefore$ ratio of concentrations

$$
\frac{\text { standard }}{\text { diluted sample }}=\frac{\mathrm{P} / 500}{\mathrm{PR} / 25 \mathrm{~V}}
$$

$\mathrm{P}$ cancels out, ie, the rate of instillation of phenol red is immaterial. The above formula then simplifies to

$$
\mathrm{R}=\frac{\mathrm{u} \times \mathrm{V}}{\mathrm{s} \times \mathrm{n}}
$$

where $\mathrm{u}=$ spectrophotometer reading of unknown,

$\mathrm{s}=$ spectrophotometer reading of standard,

and $n=\frac{500}{25}$, the ratio of the dilutions of the whole standard and $1 \mathrm{ml}$ of the gastric aspirate. 